\title{
ACUTE PANCREATITIS IN CHILDREN
}

BY

BASIL WOLMAN, M.D., M.R.C.P., D.C.H. Consultant Paediatrician. Bury and Rochdale Hospitals; Honorary Lecturer in Paediatrics, University of Manchester

Inflammation of the pancreas is rare in children and as a result may be forgotten in considering the differential diagnosis of abdominal pain, except in mumps, when nausea, vomiting, epigastric pain, and sometimes collapse suggest acute pancreatitis. Most patients recover in two or three days.

Apart from this, trauma (Venable, 1932; Adams, 1939 ; Shallow and Wagner, 1947) and disease of the biliary tract (Dobbs, 1935) may occasionally produce haemorrhagic or suppurative pancreatitis. However, these cases are few, and by far the greatest number of recorded cases have a non-specific or unidentified aetiology (Haigh, 1956; Blumenstock, Mithoefer, and Santulli, 1957).

In the last four years, three children suffering from acute pancreatitis of "non-specific" origin have been seen, and a review of the cases and the problems involved are worth discussing.

\section{Case 1}

A boy aged 10 was first seen in November, 1957, when sent into hospital with a diagnosis of acute appendicitis because of generalized severe abdominal pain and vomiting of two days' duration. On examination he had tenderness and rigidity in the right hypochondrium but no rebound tenderness. His temperature was $99^{\circ} \mathrm{F} .\left(37.2^{\circ} \mathrm{C}\right.$. $)$ and the blood count was normal.

At operation the appendix was retrocaecal but not inflamed. The pancreas was found to be enlarged and surrounded by many enlarged mesenteric glands. Some free fluid was present. Appendicectomy was performed, but the diagnosis of pancreatitis was queried. The serum amylase was found to be 80 Wohlgemuth units. Cholecystograms, done later, showed no abnormality in the gall-bladder or bile-duct.

The boy continued to have attacks of upper abdominal pain and vomiting. Serum amylase rose to $160 \mathrm{~W}$. units. Because of repeated attacks he was readmitted to hospital in June, 1959, and a sphincterotomy was performed on the ampulla of Vater. At operation the pancreatic and biliary ducts were seen satisfactorily, and adequate drainage seemed to be present. Post-operatively be was well for one month, then his attacks of pain recurred, but seemed to be confined almost entirely to the left hypochondrium with referred pain at the tip of the shoulder. He was treated with tetracycline, propantheline, and sedatives. In one attack he developed paralytic ileus with gaseous distension and free fluid which at paracentesis showed a large amount of amylase (more than 5,000 units per $100 \mathrm{ml}$.). There was also a small pleural effusion.

He was given blood and "aminosol" intravenously, and was maintained on gastro-duodenal suction. Repeated paracenteses were performed and he slowly improved. His serum amylase was 2,000 units, but by the end of 1959 it had fallen to 150 units and by March, 1960, was 75 units. Since that time he has made excellent progress and has had no further trouble.

\section{Case 2}

A boy aged 11, previously well, first complained of central abdominal pain in February, 1958. When seen in June he had already had six or seven attacks lasting three or four days at a time. On only one occasion was right shouldertip pain noted.

On admission to hospital there was fullness in the upper abdomen but no definite tenderness or guarding. No masses were palpable. Straight $x$-ray films of the chest and abdomen, barium-meal investigations, and cholecystograms were normal, as was a fractional test meal. Mantoux tests were negative. Microscopical and cultural examination of the urine and faeces showed no abnormal features. Blood sedimentation rate was $70 \mathrm{~mm}$. in one bour. The haemoglobin was $61 \%(9 \mathrm{~g} . / 100 \mathrm{ml}$.) and the white cell count was 11,000 c.mm., of which $6 \%$ were eosinophils. The bonemarrow showed some excess of reticulum cells.

In hospital he ran a low-grade fever and his abdomen became distended with fluid. Paracentesis produced about $42 \mathrm{oz}$. $(1,190 \mathrm{ml}$.) of dark-yellow fluid which showed no evidence of malignant cells or tubercle bacilli. On July 15 , at laparotomy, a large amount of fluid was drained and a normal appendix removed, but the pancreas was not examined. The mesentery was studded with white deposits. Microscopical examination of this material was suggestive of fat necrosis and pancreatitis. Serum amylase was found to be $\mathbf{8 7 0}$ Somogyi units, strongly supporting the diagnosis of pancreatitis.

Post-operatively, further abdominal distension, vomiting, pain, and paralytic ileus were relieved by gastro-duodenal intubation, intravenous aminosol, and blood transfusion. $\mathrm{He}$ was treated with cortisone, penicillin, and streptomycin, and further abdominal paracentesis had to be performed. His wounds were slow to heal, but eventually his condition improved and he was discharged from hospital on September 9, 1958, when his serum amylase had fallen to 180 S. units.

After six weeks' convalescence he seemed to be perfectly recovered and has had no further trouble.

\section{Case 3}

A boy aged 6 was admitted to hospital on May 3, 1961, having had sudden severe abdominal pain five days previously. After temporary improvement the pain recurred and was associated with persistent profuse vomiting.

On admission the upper abdomen was distended and tender. His temperature was normal but his white cells numbered 29,000/c.mm. A diagnosis of appendicitis was made and laparotomy performed. Free fluid was found in the abdomen, but the appendix, which was normal, was removed. The pancreas was not examined. When seen later he was vomiting profusely and had become very dehydrated. His upper abdomen was distended. A diagnosis of pancreatitis was made from the similarity with the other cases. His serum amylase was $1.800 \mathrm{~W}$. units.

$\mathrm{He}$ improved on gastro-duodenal suction, and was re-hydrated with intravenous fluids and tetracycline. On May 10 his serum amylase had fallen to 180 units. Thereafter he had occasional complaints of upper abdominal pain with vomiting and abdominal distension lasting for several hours at a time. Suction usually relieved these symptoms within 24 to 48 hours. Propantheline was given during this period.

At the end of June his serum amylase had risen to 2,000 units. A small pleural effusion was noted. Blood and aminosol were transfused ; steroids were also given. There was slow improvement, but at the end of July, when steroids were withdrawn, the serum amylase rose to more than 3,000 units, and the abdomen became grossly distended with free fluid. A further laparotomy was performed, the abdomen being drained of a large quantity of blood-stained fluid. Although fluid tended to recur, repeated paracenteses kept it to a minimum. Tetracycline and prednisolone were given continuously.

By the end of August he was making good progress. His abdomen was normal and his serum amylase was 130 units. $\mathrm{He}$ was maintained on a small dose of prednisolone for a further month, and since October, 1961, he has remained well.

\section{Discussion}

Clinical Picture.-All three cases occurred in boys of school age. In each case the onset was sudden with 
severe upper abdominal pain. In Case 1 it was situated mainly in the right side of the upper abdomen, whereas in Cases 2 and 3 it was situated in the epigastrium. In two cases it was referred to the shoulder-tip area. Vomiting was persistent and prolonged. In Case 3 it was bile-stained and copious, but its occurrence did not relieve the severe pain. Distension occurred in the upper abdomen and later spread, with increasing ileus, to involve the whole of the abdomen. The temperature was usually not raised, and in only one case was there a leucocytosis.

Signs.-Tenderness was noted in the upper abdomen in all cases but there was no guarding or muscle spasm. Peristaltic activity was normal at the onset, but it gradually diminished as distension occurred and ileus developed. No mass was palpable and no jaundice was seen. Cyanosis and collapse were not noted, but dehydration occurred as a result of the vomiting.

Cullen's sign (discoloration of the skin around the umbilicus) was noted only in Case 3, but this was late in the disease, in the last episode of severe ileus. Dicoloration and induration in the flank (Grey Turner's sign) was not noted.

Diagnosis.-The original diagnosis in each case was appendicitis. In all three cases laparotomy was performed for suspected appendicitis. The finding of a normal appendix with free fluid in the abdomen suggested some other cause for the trouble. Careful evaluation of the symptoms and signs such as upper abdominal pain, profuse vomiting, upper abdominal distension, and lack of fever should have ruled out appendicitis. Awareness of the possibility of pancreatitis and the obvious similarity between Cases 2 and 3 helped to make the diagnosis in the last case. An increase in serum amylase occurs within a few hours of the beginning of an acute attack. The levels decline as improvement occurs but rise again with further relapses.

Radiology.-Hulten (1928) and Poppel (1951) advocated the value of $x$-ray films in the diagnosis. The signs vary and become more pronounced as time goes on. The so-called " reversed figure 3 " is characteristic. This was called by Stiennon (1956), the epsilon sign, and is due to turgidity of the mucous membrane around the pancreatic duct and oedema of the head of the pancreas, and may be seen with or without contrast medium. Accumulation of gas may be observed in the small intestine together with the retention of fluid or contrast medium due to disordered function and stagnation. Another characteristic described by Baylin and Weeks (1944) is the presence of gaseous shadows in the tissues of the posterior abdominal wall caused by necrosis and saponification resulting in small abscesses.

\section{Treatment}

Apart from laparotomy, treatment was mainly medical. Relief of pain was important, and although morphine was avoided pethidine and chloral were used. Antispasmodics such as atropine have been used to relieve spasm of the sphincter of Oddi and to diminish pancreatic secretion. Propantheline, which can be given orally, was used in all three cases for this purpose. It has been suggested that deep $x$-ray therapy to the abdomen will also reduce pancreatic secretion, but this was not tried.

Although the causal agent is unknown, and there is some doubt about whether pancreatitis is a bacterial disease, antibiotics are usually recommended. Tetracycline was used in all cases. Steroids such as prednisolone, given in doses of $10 \mathrm{mg}$. three times a day, seemed to have a beneficial effect. In Case 3, however, withdrawal, even after one month, was associated with a flare-up in the condition which seemed to be due to the continued activity of the disease rather than to a simple rebound phenomenon.

Paralytic ileus occurred rather insidiously and was difficult to manage, but abdominal distension may be minimized by continuous gastroduodenal suction and intravenous fluids. The prompt restoration of blood volume is urgent. The essential loss concerns the plasma fraction mainly, and the replacement fluids should include plasma or a plasma substitute or albuminamino-acid product. Fluid loss seems to be progresssive and total requirements usually exceed initial estimates. Intravenous glucose-saline solution in sufficient quantities to supply daily needs are used to supplement the plasma albumin-amino-acid solution.

There is usually a secondary anaemia, so that blood transfusion, repeated if necessary, is particularly valuable.

Operation is undertaken usually as a result of a mistaken diagnosis, but establishment of the correct diagnosis and the drainage of fluid from the peritoneal cavity seem to be eminently reasonable grounds for laparotomy. Fluid can be removed quite satisfactorily, however, by repeated abdominal paracentesis, and if the diagnosis is certain there is no reason for laparotomy.

Sphincterotomy, first advocated by Colp and Doubilet (1938) and Doubilet and Mulholland (1948), has been suggested as a means of treating the subacute or chronic case after the acute initial attack has subsided. This operation was carried out in Case 1 , but improvement lasted only about one month before the symptoms recurred; the disease then gradually subsided with medical management.

In general, it is concluded that conservative management is to be preferred, particularly in childhood.

\section{Summary}

Three schoolboys with non-specific pancreatitis have been treated in the last four years.

The clinical features of the disease and the diagnostic problems presented are discussed.

Apart from "diagnostic" laparotomy, treatment was conservative except in one case when sphincterotomy was only partially and temporarily successful.

I am grateful to my surgical colleagues for referring these patients and to Professor Wilfrid F. Gaisford for help in the preparation of the manuscript.

\section{REFERENCES}

Adams, A. W. (1939). Brit. med. J., 2, 854.

Baylin, G. J., and Weeks, K. D. (1944). Radiology, 42, 466. Blumenstock, D. A., Mithoefer, J., and Santulli, T. V. (1957). Pediatrics, 19. 1002

Colp, R., and Doubilet, H. (1938). Surgery, 4, 837.

Dobbs, R. H. (1935). Lancet, 2, 989.

Doubilet, H., and Mulholland, J. H. (1948). Ann. Surg., 128. 609.

Haigh, E. (1956). Arch. Dis. Childh., 31, 273.

Hulten, O. (1928). Acta radiol. (Stockh.), 9, 222.

Poppel, M. H. (1951). Roentgen Manifestations of Pancreatic Disease. Thomas, Springfield, Illinois.

Shallow, T. A., and Wagner, F. B. (1947). Ann. Surg., 125, 66.

Stiennon, O. A. (1956). Amer. J. Roentgenol., 75, 282.

Venable, C. S. (1932). Surg. Gynec. Obstet., 55, 652. 